\title{
EFEITO DE UM EVENTO EXTREMO DE ENCHENTE SOBRE OS DECÁPODOS INFRALITORAIS DO ESTUÁRIO DO ITAJAÍ-AÇU, SC, BRASIL
}

\author{
LEITE, I. P. \& PEZZUTO, P. R.* \\ Universidade do Vale do Itajaí - UNIVALI \\ Centro de Ciências Tecnológicas da Terra e do Mar - CTTMar \\ *Contact author: pezzuto@univali.br
}

\begin{abstract}
Leite, I. P. \& Pezzuto, P. R. (2012) Effect of an extreme flooding event on the infralittoral decapods of the Itajaí-Açu estuary, SC, Brazil. Braz. J. Aquat. Sci. Technol. 16(2): 13-26. eISSN 1983-9057. Estuaries are coastal water bodies with great economic and biological importance. The benthic organisms play a significant role in these environments as regulators or modifiers of physical, chemical and biological processes. This study aimed to evaluate the spatial and temporal distribution of the infralittoral decapods in the Itajaí-Açu estuary, investigating factors that influence their distribution and possible effects of a flood event on the benthic community. Six sampling points were established along the longitudinal gradient of the estuary. Monthly samples were taken with otter trawls between May 2008 and July 2010. The abundance and biomass of the crustaceans were analyzed using descriptive statistics. Variations in the physicochemical data of the water column, and its possible effects over the decapods, were also evaluated. The results showed that $\mathrm{pH}$, salinity and dissolved oxygen are related to the penetration of the salt wedge, while temperature shows a seasonal pattern. The estuary showed a low richness (14 species), mainly in the two months after the flood of November 2008, and high dominance. It was possible to infer that many factors act on the estuary making it difficult to establish clear relationships between the biota and environmental variables in particular. There was an increase in abundance and biomass between February and July 2009 , which suggests that the fauna was able to recover from the flood.
\end{abstract}

Keywords: Estuarine ecology, distribution, biomass, Crustacea, Brazil

\section{INTRODUÇÃO}

Estuários são ambientes de transição entre o continente e o oceano, e estão sujeitos a influências tanto continentais como marinhas, entre elas o aporte de água continental, a salinidade, efeitos de marés e influência antrópica (Miranda et al., 2002; Kapusta, 2005). Esses ambientes são de grande importância econômica e biológica para muitos organismos, porém, são encontrados poucos estudos sobre os ambientes estuarinos ao longo do litoral brasileiro, principalmente sobre a ecologia desses ecossistemas, o que dificulta a tomada de decisões para o desenvolvimento sustentável (Schettini, 2001).

Nos estuários a interação entre coluna da água e o sedimento é marcante, afetando principalmente os organismos que vivem junto ao fundo, a fauna bentônica. Assim, o meio bentônico apresenta um forte efeito estruturador, regulando ou modificando a maioria dos processos físicos, químicos e biológicos em sistemas estuarinos (Day Jr. et al., 1989).

Dentre os organismos bentônicos estuarinos, os crustáceos decápodos apresentam grande importância, estando envolvidos em processos que incluem a bioturbação, a regeneração de nutrientes, a predação sobre outros elementos do macrobentos, consumo de depósitos e necrofagia ou, ainda, servindo como fonte de alimento para o necton demersal (Day Jr. et al., 1989) e apresentando grande valor comercial (Ferreira
\& D'Incao, 2008). Os estuários fazem parte do ciclo de vida de muitas espécies de crustáceos decápodos (Dame \& Allen, 1996), e as condições ambientais e pressões que agem sobre esses ecossistemas são, consequentemente, variáveis que determinarão como e quando as diferentes espécies estarão presentes.

A bacia do rio Itajaí-Açu é uma das mais importantes do estado de Santa Catarina (Porath, 2004; Schettini, 2001). O baixo estuário do Itajaí-Açu está sujeito a uma grande quantidade de impactos que podem afetar a fauna, como a movimentação de navios e as dragagens devido às atividades portuárias, e um grande aporte de poluentes e esgotos domésticos oriundos da intensa ocupação das suas margens (Veado, 2008).

Além dos impactos antrópicos, o estuário do rio Itajaí-Açu sofre aumentos repentinos e substanciais do volume de água decorrentes de enchentes. A partir da década de 1920 tem aumentado o número de pequenas enchentes na região, devido ao incremento da ocupação no Alto Vale do Itajaí. Em novembro de 2008, no entanto, uma enchente de proporções catastróficas acometeu este estuário, causando severos impactos econômicos e sociais na região. Estudos sobre enchentes indicam que esses eventos extremos podem afetar significativamente a fauna estuarina, causando diminuição na biomassa e riqueza das espécies (Cardoso et al., 2008). 


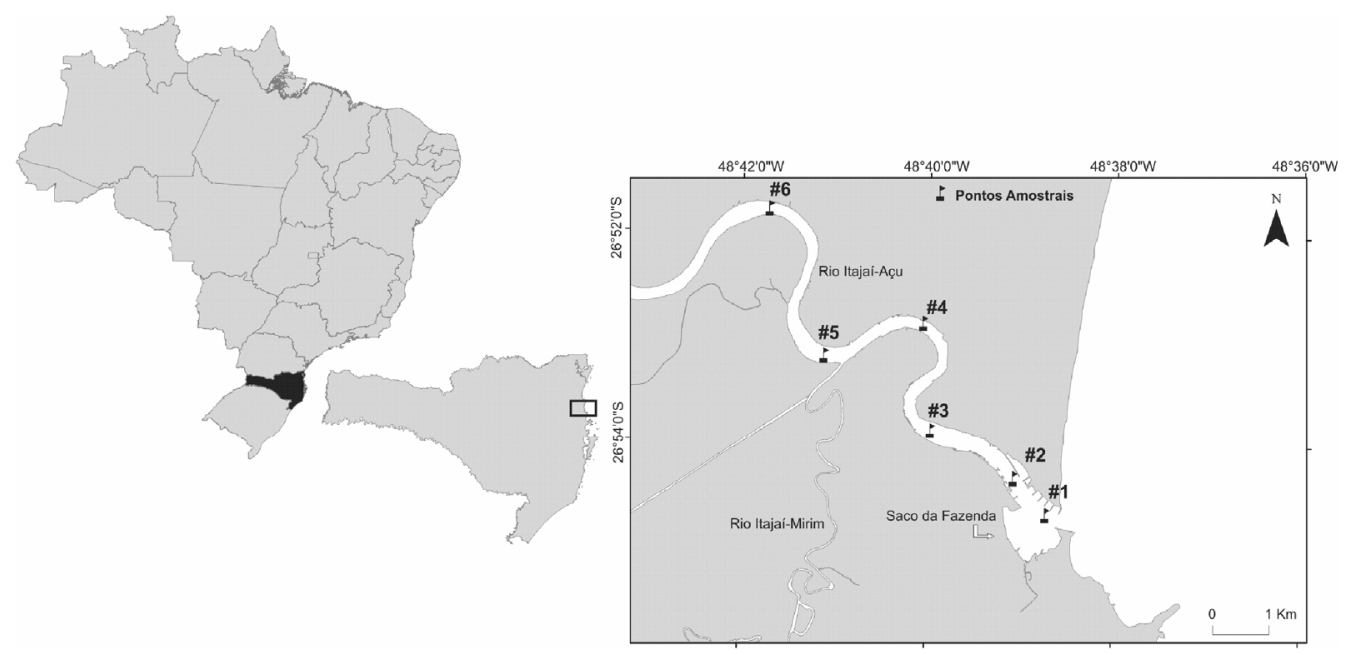

Figura 1 - Localização dos pontos de coleta no estuário do rio Itajaí-Açu (SC) entre maio de 2008 a julho de 2009.

A fauna do estuário do rio Itajaí-Açu tem sido alvo de diversos estudos ecológicos nos últimos anos (e.g. Veado, 2008; Antunes, 2010). Entretanto, ainda são poucos os trabalhos sobre os organismos bentônicos desse estuário, entre eles os crustáceos. As únicas informações disponíveis sobre os decápodos foram obtidas numa pequena enseada protegida adjacente à sua foz, o Saco da Fazenda, onde Branco \& Freitas Jr. (2009) encontraram Callinectes danae dominando o ambiente de abril de 2000 a março de 2005.

Dessa forma, considerando a grande proporção da enchente ocorrida em novembro de 2008, a importância ecológica e econômica dos macrocrustáceos bentônicos estuarinos e a crescente pressão antrópica sofrida por esse estuário, este trabalho teve como objetivo descrever as mudanças provocadas por um evento extremo de enchente na composição e na abundância relativa dos decápodos infralitorais do baixo-estuário do Itajaí-Açu. O trabalho apresenta ainda dados inéditos sobre esse grupo de organismos ao longo de um gradiente salino, destacando quais os principais parâmetros que afetam sua distribuição espaço-temporal e possíveis forçantes externas que modificam a estrutura da assembleia desses organismos.

\section{MATERIAL E MÉTODOS}

\section{Amostragens}

O estudo foi realizado em 6 pontos amostrais dispostos no canal do estuário entre a sua foz e um ponto localizado à montante da desembocadura do rio Itajaí-Mirim (Figura 1, Tabela 1). Treze amostragens mensais foram realizadas entre maio de 2008 e julho de 2009. Não houve coletas em outubro e novembro, devido à forte vazão do rio em decorrência das intensas chuvas, agravadas pela enchente ocorrida no final do mês de novembro no litoral catarinense (Figura 2). Também não foi possível realizar a amostragem no ponto 1 em junho de 2009, devido à grande quantidade de entulho coletado que não possibilitou que a rede fosse puxada para dentro da embarcação.

As coletas foram efetuadas com uma embarcação motorizada tipo baleeira, com 10 metros de comprimento e motor de $45 \mathrm{Hp}$. Em cada estação e data foi realizado um arrasto de popa com uma rede de portas com malha de $20 \mathrm{~mm}$ no corpo e no ensacador, medidos entre nós opostos com a malha esticada. Cada arrasto teve a duração média de 10 minutos, tendo sido realizado em velocidade média de 2 nós. Os crustáceos foram separados do resto da captura em cada lance, acondicionados em sa-

Tabela 1 - Localização dos pontos de coleta no estuário do rio Itajaí-Açu (SC) entre maio de 2008 a julho de 2009.

\begin{tabular}{cccc}
\hline $\begin{array}{c}\text { Ponto } \\
\text { Amostral }\end{array}$ & \multirow{2}{*}{ Nome do Ponto } & \multicolumn{2}{c}{ Posição Geográfica } \\
Latitude $\left({ }^{\circ} \mathrm{S}\right)$ & Longitude ( $\left.{ }^{\circ} \mathrm{W}\right)$ \\
\hline 1 & Foz Itajaí-Açu & $26^{\circ} 54,783^{\prime}$ & $48^{\circ} 38,570^{\prime}$ \\
2 & Cepsul & $26^{\circ} 54,554^{\prime}$ & $48^{\circ} 38,949^{\prime}$ \\
3 & Porto Itajaí & $26^{\circ} 53,896^{\prime}$ & $48^{\circ} 40,013^{\prime}$ \\
4 & Pepsico & $26^{\circ} 52,904^{\prime}$ & $48^{\circ} 40,117^{\prime}$ \\
5 & Desembocadura Itajaí-Mirim & $26^{\circ} 53,189^{\prime}$ & $48^{\circ} 41,263^{\prime}$ \\
6 & Igreja & $26^{\circ} 51,930^{\prime}$ & $48^{\circ} 41,449^{\prime}$ \\
\hline
\end{tabular}




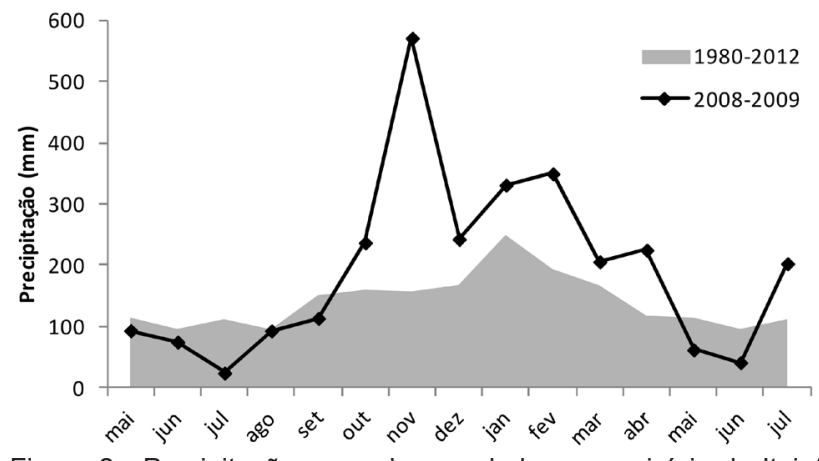

Figura 2 - Precipitação mensal acumulada no município de Itajaí - SC. Série 1- Valores registrados no período de maio de 2008 e julho de 2009. Série 2 - Médias históricas para os meses de janeiro a dezembro considerando o período de janeiro de 1980 a março de 2012. Fonte: Araújo, S. A. \& Reis, F. H. Relatório Climatológico. Estação meteorológica automática . Universidade do Vale do Itajaí. Itajaí- SC. Laboratório de Climatologia.

cos plásticos etiquetados e mantidos congelados em freezer até o processamento em laboratório. Em função de dificuldades operacionais como elevada quantidade de entulhos e do grande volume de material capturado em certos lances, foi necessário reduzir o tempo de arrasto e/ou quartear a captura ainda a bordo. Os tempos de arrasto efetivamente realizados e os volumes totais e quarteados das capturas foram anotados, e a partir daí os dados foram padronizados para números ou biomassa de indivíduos capturados por dez minutos de arrasto. Simultaneamente, foram registrados dados físico-químicos da água de fundo (salinidade, $\mathrm{pH}$, oxigênio dissolvido e temperatura da água), a partir de um Multianalisador portátil (Water Checker U-10 Horiba) ou de uma Sonda multiparâmetros (Multiparameter Water Quality Sonde YSI 6600 V2). A profundidade local não pôde ser medida precisamente, mas foram registradas as profundidades máximas atingidas pelo multianalisador ou pela sonda, antes de tocarem o fundo.

\section{Processamento em laboratório}

A identificação dos Brachyura foi efetuada ao menor nível taxonômico possível de acordo com Melo (1996) e Coelho \& Santos (2003). Já os camarões foram identificados a partir de D'Incao (1995) e Costa et al. (2003). As amostras, por espécie, data e estação foram pesadas (peso úmido em $\mathrm{g}$ ) com balança digital, com precisão de $0,01 \mathrm{~g}$.

\section{Análise dos dados}

A partir dos dados originais, foram calculados os valores de biomassa e abundância padronizados por 10 minutos de arrasto de cada espécie em cada uma das seis estações durante os 13 meses de amostragem.

Foi verificada então a variação da abundância e da biomassa total e por espécie ao longo dos pontos amostrais, considerando todo o período de estudo. A variação mensal desses descritores também foi examinada para as cinco principais espécies capturadas e também para o total dos crustáceos, Brachyura e camarões, separadamente.

A relação entre as variáveis ambientais e as principais espécies amostradas foi examinada através do coeficiente de correlação de Spearman, com nível de significância de 0,05. Gráficos do tipo Box-plot com os valores de salinidade, temperatura $\left({ }^{\circ} \mathrm{C}\right)$, concentração de oxigênio dissolvido $(\mathrm{mg} / \mathrm{l})$ e $\mathrm{pH}$, em que as principais espécies foram amostradas foram gerados, visando identificar intervalos de condições ambientais sob as quais cada uma das espécies foi coletada.

\section{RESULTADOS}

\section{Variáveis abióticas}

A profundidade apresentou os maiores valores próximo a entrada do estuário (pontos 1, 2 e 3) e os menores no seu interior (pontos 4, 5 e 6) (Tabela 2). Nas coletas de 2008 a profundidade mostrou menor amplitude de variação entre as estações (3 a 9 m),

Tabela 2 - Valores médios ( $\pm D P$ ), mínimos e máximos das variáveis ambientais nos pontos amostrados no estuário do rio Itajaí-Açu entre maio de 2008 a julho de 2009. Valores de temperatura, salinidade, oxigênio dissolvido (OD) e pH referem-se à água de fundo.

\begin{tabular}{ccccccc}
\hline \hline \multirow{2}{*}{ Variável } & \multicolumn{5}{c}{ Ponto } \\
\cline { 2 - 6 } & 1 & 2 & 3 & 4 & 5 & 6 \\
\hline $\begin{array}{c}\text { Profundidade } \\
(\mathrm{m})\end{array}$ & $9,5( \pm 1,2)$ & $9,5( \pm 1,6)$ & $9,7( \pm 1,1)$ & $7,0( \pm 1,8)$ & $6,3( \pm 1,9)$ & $6,3( \pm 0,9)$ \\
& $(8,0-12,0)$ & $(7,0-12,1)$ & $(7,9-11,2)$ & $(3,0-9,2)$ & $(3,0-9,0)$ & $(5,0-7,9)$ \\
Temperatura & $22,0( \pm 2,9)$ & $21,8( \pm 2,8)$ & $21,8( \pm 2,8)$ & $21,7( \pm 2,9)$ & $21,7( \pm 2,9)$ & $21,7( \pm 2,9)$ \\
$\left({ }^{\circ} \mathrm{C}\right)$ & $(18,3-25,9)$ & $(18,5-25,7)$ & $(18,5-25,7)$ & $(17,8-26,0)$ & $(18,3-26,5)$ & $(18,1-26,4)$ \\
Salinidade & $27,1( \pm 4,2)$ & $27,3( \pm 5,2)$ & $26,2( \pm 4,3)$ & $24,0( \pm 8,7)$ & $19,8( \pm 10,4)$ & $17,7( \pm 11,0)$ \\
& $(18,2-33,5)$ & $(15,4-34,1)$ & $(19,6-34,0)$ & $(5,2-33,9)$ & $(2,2-33,6)$ & $(0,5-33,3)$ \\
OD $(\mathrm{mg} / \mathrm{l})$ & $6,5( \pm 2,0)$ & $6,1( \pm 1,9)$ & $5,0( \pm 2,3)$ & $5,6( \pm 1,6)$ & $5,9( \pm 1,4)$ & $5,1( \pm 1,7)$ \\
& $(1,7-9,2)$ & $(2,0-8,7)$ & $(0,6-8,0)$ & $(2,7-8,2)$ & $(3,3-8,0)$ & $(3,1-7,7)$ \\
$\mathrm{pH}$ & $8,1( \pm 0,3)$ & $8,1( \pm 0,3)$ & $8,0( \pm 0,4)$ & $7,9( \pm 0,5)$ & $7,7( \pm 0,5)$ & $7,6( \pm 0,6)$ \\
& $(7,8-8,7)$ & $(7,6-8,7)$ & $(7,3-8,7)$ & $(6,5-8,4)$ & $(6,9-8,7)$ & $(6,1-8,4)$ \\
\hline \hline
\end{tabular}


enquanto em 2009 estes valores oscilaram entre 4 a $12 \mathrm{~m}$, aproximadamente (Figura 3).

A temperatura da água de fundo apresentou comportamento similar entre os pontos (Tabela 2) com variação sazonal entre valores máximos $\left(26,5^{\circ} \mathrm{C}\right)$ na primavera e verão e mínimos $\left(17,8^{\circ} \mathrm{C}\right)$ durante 0 inverno (Figura 3).

A variação espacial da salinidade da água de fundo seguiu o padrão esperado para esse estuário, sendo maior próximo a foz (ponto 1) diminuindo em direção ao seu interior (ponto 6) (Tabela 2). Em geral, ela apresentou valores elevados no outono e inverno e menores no verão, chegando quase a zero em alguns pontos de coleta (Tabela 2 e Figura 3 ).
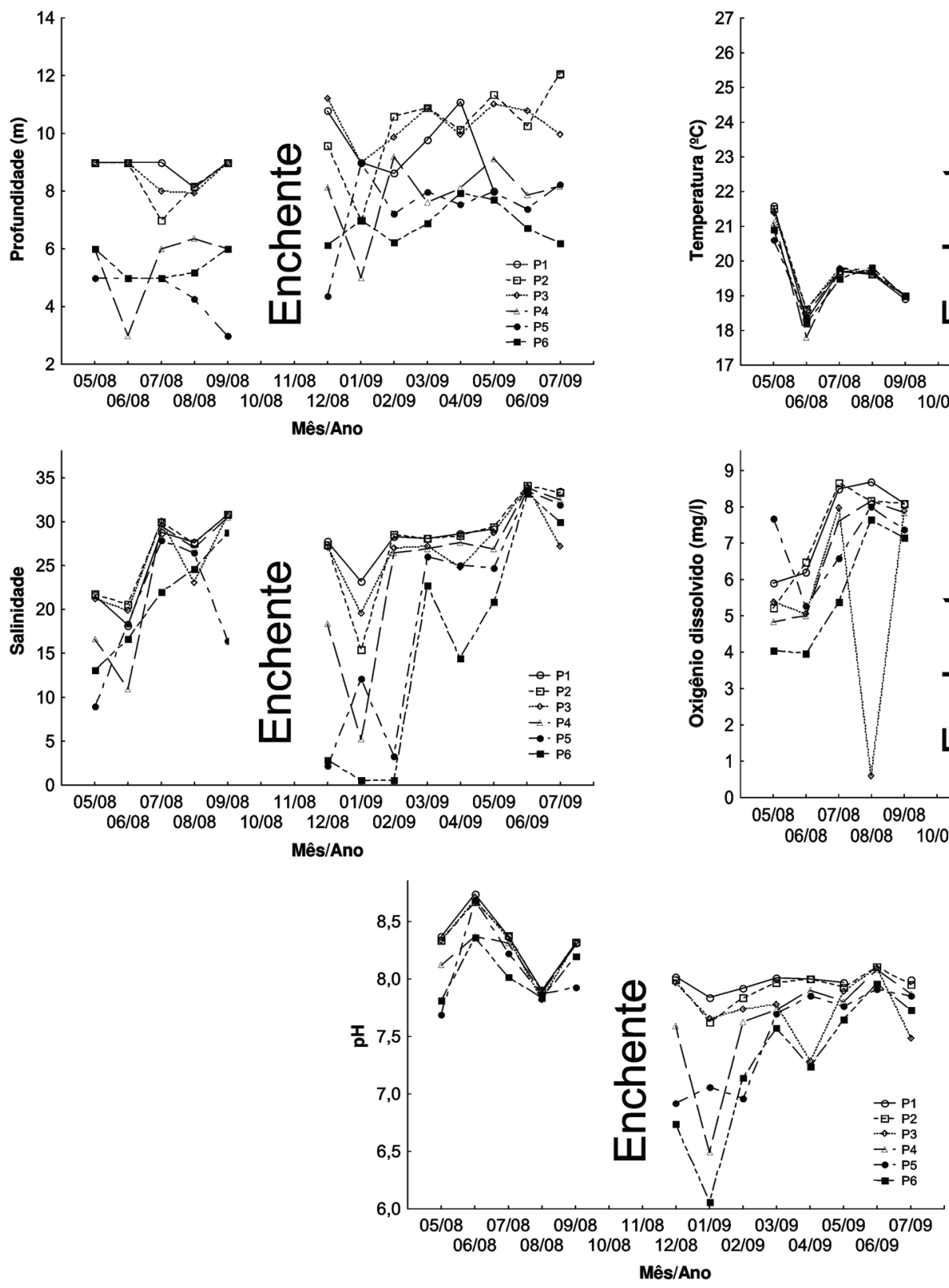

Figura 3 - Flutuação da profundidade e das variáveis abióticas da água de fundo nas estações de coleta efetuadas no estuário do rio Itajaí-Açu entre maio de 2008 e julho de 2009. Em outubro e novembro de 2008 não foram realizadas amostragens.
A concentração de oxigênio dissolvido (OD) mostrou ampla variação em todos os pontos, tendendo, no entanto, a valores médios ligeiramente maiores próximo a foz do estuário (Tabela 2). Foram observadas concentrações mais elevadas no inverno de 2008 em todos os pontos, exceto no ponto 3 onde valores próximos a zero ocorreram em agosto de 2008 (Figura 3). Com exceção do ponto 5, o OD teve um decréscimo (para aproximadamente $2 \mathrm{mg} / \mathrm{l}$ ) no mês de fevereiro de 2009. Em geral todos os pontos seguiram o mesmo padrão, com amplas variações ao longo do período de estudo (Tabela 2 e Figura 3).

Os valores médios de $\mathrm{pH}$ também foram maiores na foz do estuário e decresceram para o
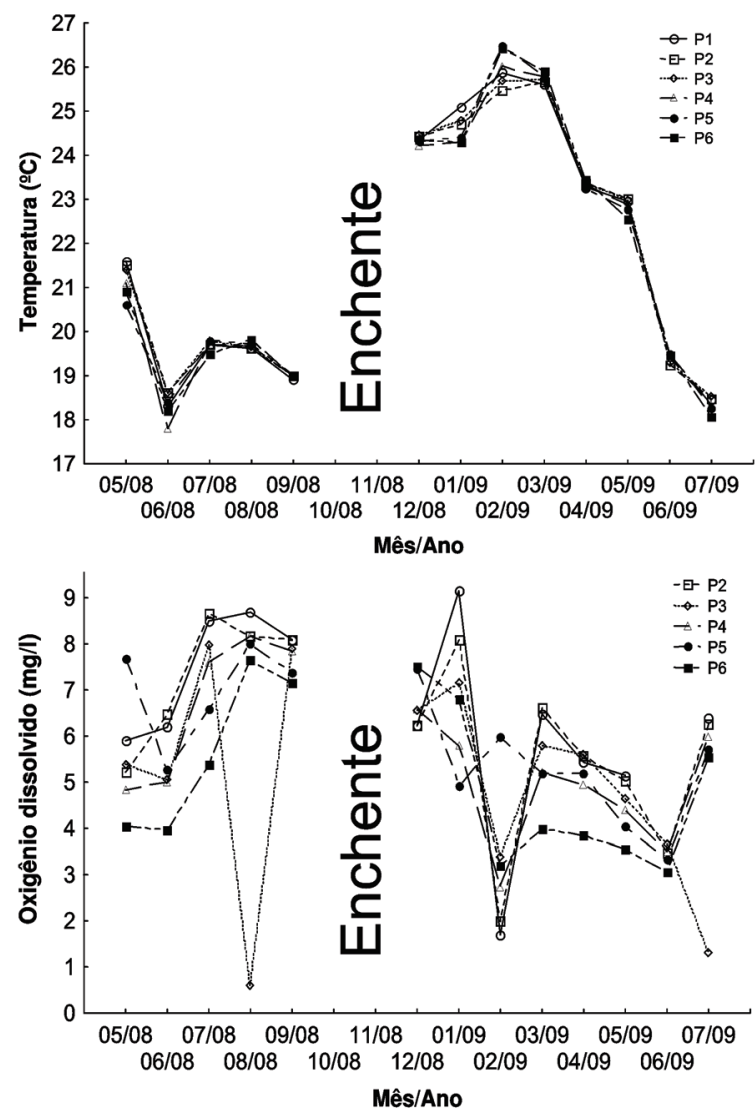
interior (Tabela 2). Em 2008 a flutuação do pH foi relativamente similar entre os pontos. Os maiores valores ocorreram no inverno de 2008 e os menores foram observadores durante o verão de 2009 (Figura 3).

Em dezembro de 2008, na primeira amostragem após a enchente, observou-se uma grande redução na salinidade e no $\mathrm{pH}$ da água de fundo nos pontos 5-6, indicando que a cunha salina, antes bem estabelecida, foi empurrada pela enchente até uma área mais a jusante do estuário (Figura 3). A cunha salina só retornou a uma posição semelhante ao período anterior à enchente em março de 2009. Após a enchente foram observados, em geral, valores inferiores de $\mathrm{pH}$ e de oxigênio dissolvido, além de um aumento progressivo na profundidade (Figura 3).

\section{Abundância e distribuição espacial e temporal das espécies}

Durante o período de estudo foram amostradas 14 espécies ou morfotipos de siris e de camarões (Tabela 3) totalizando 2399 exemplares e uma biomassa total de 39.978,8g (Tabelas 4 e 5). Apenas um exemplar de Litopenaeus schmitti e Hippolytidae sp. e quatro indivíduos do siri invasor Charybdis hellerii foram coletados. Foi registrada a ocorrência de quatro espécies de Callinectes que, juntas, contribuíram com $65,6 \%$ da abundância e 95,1\% da biomassa total, sendo que Callinectes danae dominou nas amostra- gens, participando com $59,1 \%$ da abundância e $72,4 \%$ da biomassa (Tabelas 4 e 5).

A abundância dos decápodos foi relativamente similar entre os pontos, exceto no ponto 2, onde foi observado o seu menor valor (Tabela 4). Os maiores valores ocorreram nos pontos 1 , reflexo do elevado número de camarões e no 4 que foi representado principalmente por Brachyura. Comparada à abundância, a biomassa total mostrou uma variação espacial mais acentuada. Os menores valores foram observados nos pontos 1 e 2 e o maior no ponto 5 . A abundância de Brachyura foi maior mais a montante do estuário e menor próximo a sua foz (pontos 1 e 2), assim como a sua biomassa (Tabelas 4 e 5). A variação espacial do número de camarões foi semelhante ao da sua biomassa, porém, com uma maior variação entre os pontos (Tabelas 4 e 5). A contribuição dos camarões na biomassa total foi bem menor do que a de Brachyura como pode ser observado na Tabela 5. De fato, os Brachyura contribuiram com $95,4 \%$ da biomassa total de macrocrustáceos do estuário do Itajaí-Açu (Tabela 5).

A flutuação temporal da abundância e da biomassa do total de organismos coletados e dos braquiúros foi similar ao longo do estudo (Figura 4). Nota-se dois períodos marcantes da ocorrência de indivíduos nas amostragens, o primeiro entre julho e setembro de 2008 , reflexo principalmente da elevada

Tabela 3 - Listagem das espécies coletadas no estuário do rio Itajaí-Açu entre maio de 2008 a julho de 2009.

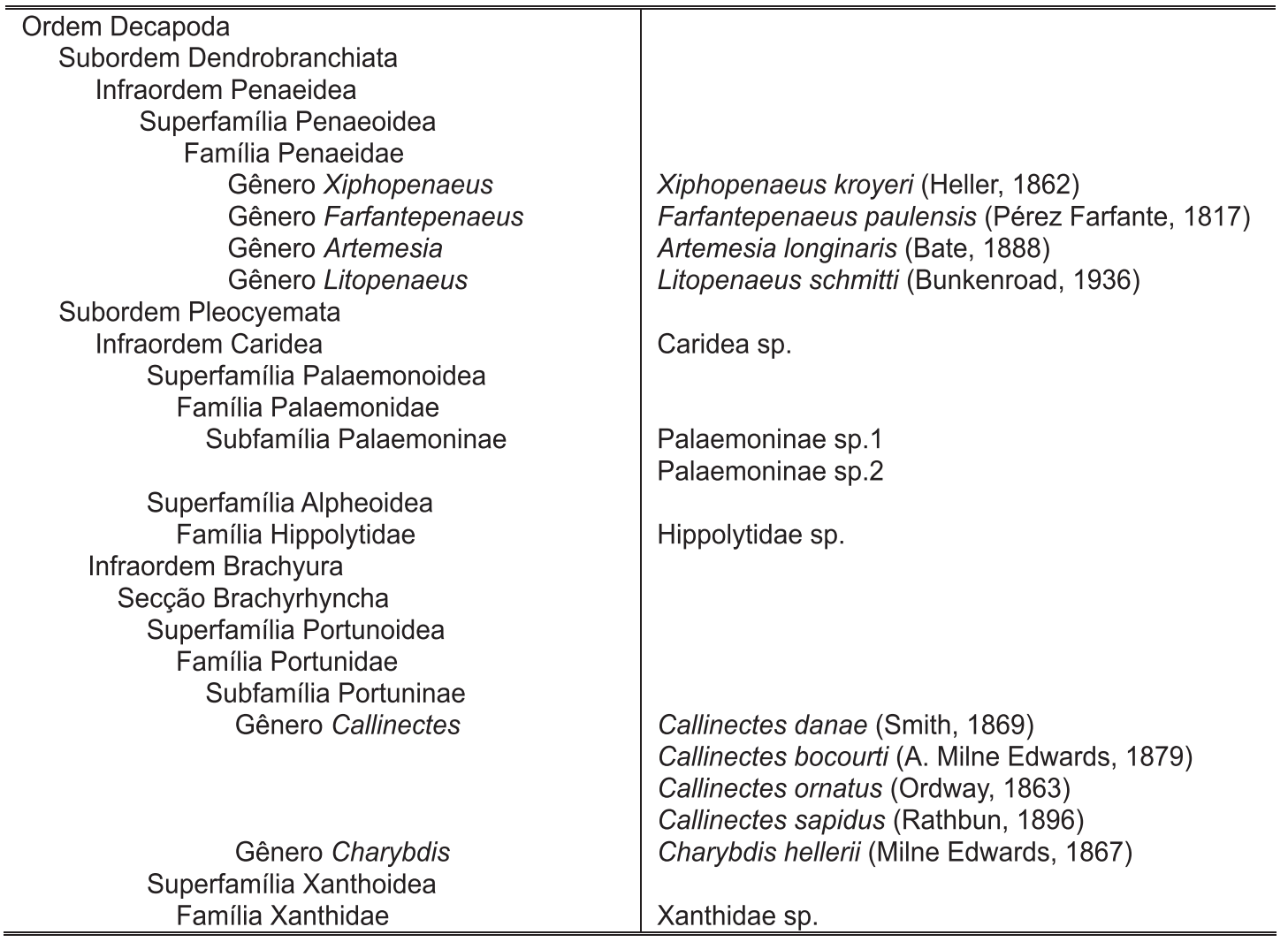


Tabela 4: Abundância numérica de cada espécie em cada ponto e sua participação relativa na abundância total (\%) no estuário do rio Itajaí-Açu entre maio de 2008 a julho de 2009.

\begin{tabular}{|c|c|c|c|c|c|c|c|c|}
\hline \multirow{2}{*}{ Espécies } & \multicolumn{6}{|c|}{ Ponto } & \multirow{2}{*}{ Total } & \multirow{2}{*}{$\%$} \\
\hline & 1 & 2 & 3 & 4 & 5 & 6 & & \\
\hline Xiphopenaeus kroyeri & 378 & 28 & 66 & 166 & 52 & 23 & 713 & 29,7 \\
\hline $\begin{array}{l}\text { Farfantepenaeus } \\
\text { paulensis }\end{array}$ & 0 & 8 & 25 & 6 & 12 & 31 & 82 & 3,4 \\
\hline Artemesia longinaris & 2 & 0 & 0 & 0 & 0 & 0 & 2 & 0,1 \\
\hline Litopenaeus schmitti & 0 & 0 & 1 & 0 & 0 & 0 & 1 & 0,0 \\
\hline Caridae sp. & 2 & 0 & 1 & 0 & 0 & 0 & 3 & 0,1 \\
\hline Palaemoninae sp.1 & 0 & 0 & 0 & 0 & 4 & 6 & 10 & 0,4 \\
\hline Palaemoninae sp.2 & 0 & 0 & 0 & 0 & 6 & 0 & 6 & 0,3 \\
\hline Hippolytidae sp. & 0 & 0 & 0 & 1 & 0 & 0 & 1 & 0,0 \\
\hline Callinectes danae & 66 & 86 & 313 & 325 & 242 & 384 & 1416 & 59,1 \\
\hline Callinectes bocourti & 2 & 0 & 1 & 0 & 0 & 0 & 3 & 0,1 \\
\hline Callinectes ornatus & 52 & 21 & 4 & 2 & 0 & 0 & 79 & 3,3 \\
\hline Callinectes sapidus & 2 & 0 & 4 & 14 & 46 & 9 & 75 & 3,1 \\
\hline Charybdis hellerii & 4 & 0 & 0 & 0 & 0 & 0 & 4 & 0,2 \\
\hline Xantidae sp. & 0 & 0 & 0 & 0 & 0 & 4 & 4 & 0,2 \\
\hline Total & 508 & 143 & 415 & 514 & 362 & 457 & 2399 & \\
\hline
\end{tabular}

abundância de Brachyura e o segundo entre fevereiro e julho de 2009, mês onde se observou o maior valor registrado em todo o período (Figura 4). É importante destacar que nos meses imediatamente seguintes à enchente, a abundância total foi muita baixa, com valores próximos a zero. Os camarões estiveram pouco representados no estuário entre maio e setembro de 2008. Sua abundância máxima foi observada em fevereiro de 2009 , com altos valores também nos dois meses seguintes, influenciando fortemente a abun- dância total de crustáceos nesse período. Na amostra de maio de 2008 não ocorreram camarões (Figura 4). A biomassa deste grupo seguiu exatamente o padrão descrito para sua abundância.

As espécies mais abundantes e que apresentaram a maior freqüência de ocorrência no estuário foram Callinectes danae, Xiphopenaeus kroyeri, Farfantepenaeus paulensis, Callinectes ornatus e Callinectes sapidus (Tabela 4). As maiores abundâncias totais ocorreram nos pontos 4 e 1 e foram deter-

Tabela 5 - Biomassa $(\mathrm{g})$ de cada espécie em cada ponto e sua participação relativa na biomassa total (\%) no estuário do rio Itajaí-Açu entre maio de 2008 a julho de 2009.

\begin{tabular}{lcccccccc}
\hline \multirow{2}{*}{ Espécies } & \multicolumn{7}{c}{ Ponto } & \multicolumn{2}{c}{ Total } & $\%$ \\
\cline { 2 - 6 } & 1 & 2 & 3 & 4 & 5 & 6 & & \\
\hline Xiphopenaeus kroyeri & 922,6 & 54,3 & 121,7 & 237,1 & 75,1 & 21,0 & 1431,9 & 3,6 \\
Farfantepenaeus & 0,0 & 58,2 & 95,9 & 6,5 & 58,1 & 96,9 & 315,6 & 0,8 \\
paulensis & 5,7 & 0,0 & 0,0 & 0,0 & 0,0 & 0,0 & 5,7 & 0,0 \\
Artemesia longinaris & 0,0 & 0,0 & 7,1 & 0,0 & 0,0 & 0,0 & 7,1 & 0,0 \\
Litopenaeus schmitti & 1,4 & 0,0 & 0,9 & 0,0 & 0,0 & 0,0 & 2,2 & 0,0 \\
Caridae sp. & 0,0 & 0,0 & 0,0 & 0,0 & 55,6 & 14,1 & 69,7 & 0,2 \\
Palaemoninae sp.1 & 0,0 & 0,0 & 0,0 & 0,0 & 30,5 & 0,0 & 30,5 & 0,1 \\
Palaemoninae sp.2 & 0,0 & 0,0 & 0,0 & 1,3 & 0,0 & 0,0 & 1,3 & 0,0 \\
Hippolytidae sp. & 1810,5 & 2521,3 & 7782,7 & 5366,8 & 5026,8 & 6437,3 & 28945,4 & 72,4 \\
Callinectes danae & 80,0 & 0,0 & 60,1 & 0,0 & 0,0 & 0,0 & 140,1 & 0,4 \\
Callinectes bocourti & 559,1 & 350,4 & 3,5 & 12,7 & 0,0 & 0,0 & 925,7 & 2,3 \\
Callinectes ornatus & 160,7 & 0,0 & 156,8 & 1820,6 & 5218,3 & 627,1 & 7983,5 & 20,0 \\
Callinectes sapidus & 114,9 & 0,0 & 0,0 & 0,0 & 0,0 & 0,0 & 114,9 & 0,3 \\
Charybdis hellerii & 0,0 & 0,0 & 0,0 & 0,0 & 0,0 & 5,2 & 5,2 & 0,0 \\
Xantidae sp. & 3654,9 & 2984,2 & 8228,6 & 7444,9 & 10464,5 & 7201,6 & 39978,8 & \\
\hline \multicolumn{1}{c}{ Total } & & & & & & & &
\end{tabular}



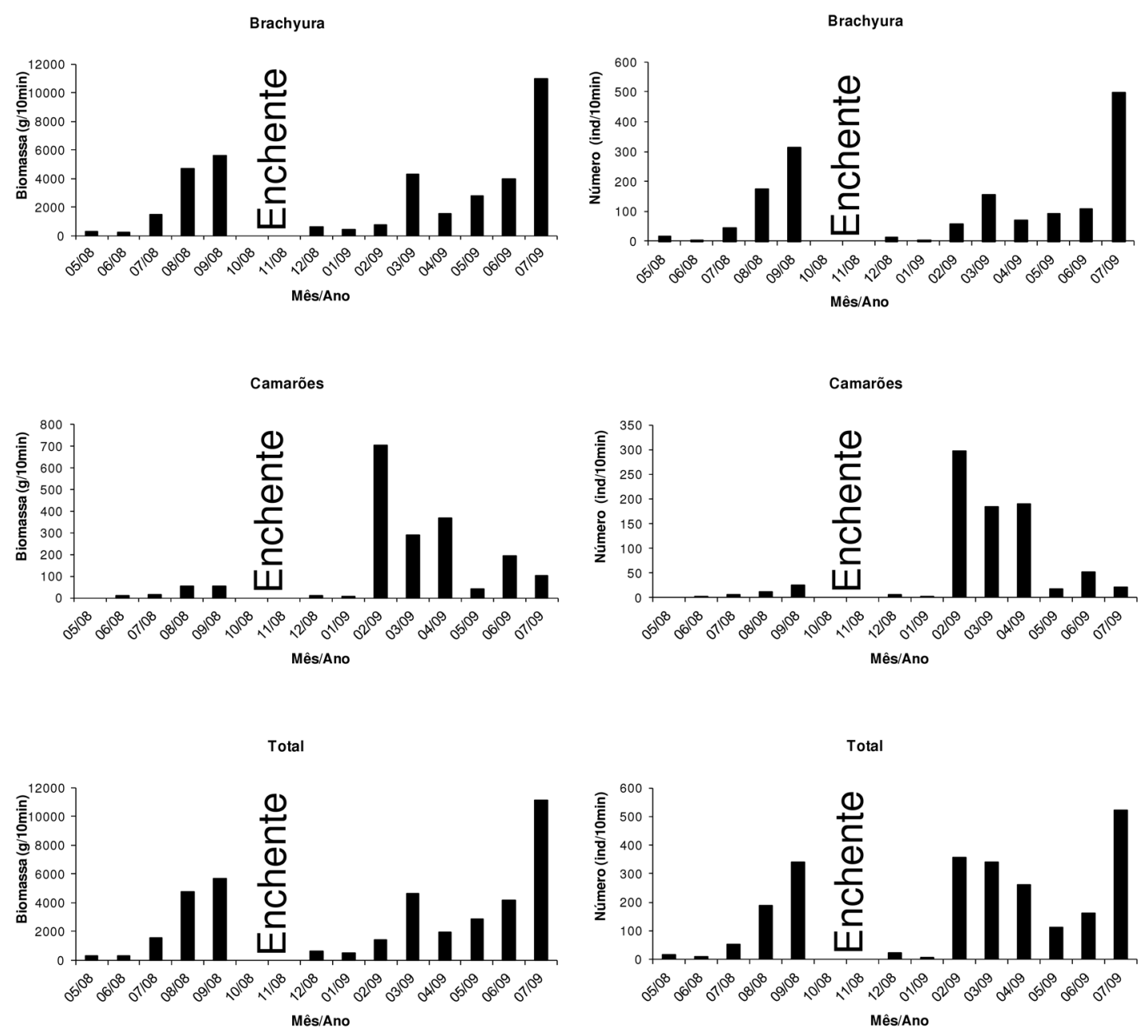

Figura 4 - Variação temporal da abundância e biomassa para o total de crustáceos, assim como de camarões e de Brachyura no estuário do rio Itajaí-Açu, entre maio de 2008 e julho de 2009. Em outubro e novembro de 2008 não foram realizadas amostragens.

minadas, respectivamente, pela presença de C. danae e de $X$. kroyeri. Já a menor abundância foi observada no ponto 2. Em relação aos Brachyura, C. ornatus se distribuiu principalmente junto à foz (pontos 1 e 2 ) (92,3\% dos indivíduos da espécie), enquanto C. danae ocupou principalmente os pontos 3, 4 e 6 e $C$. sapidus os pontos 4 e 5 . Em relação aos camarões, $X$. kroyeri se distribuiu ao longo de todo o perfil amostrado, com picos nos pontos 1 e 4. F. paulensis não foi observado no ponto 1, e apresentou maior abundância nos pontos 3 e 6 (Tabela 4).

Callinectes danae, C. sapidus, $X$. kroyeri e C. ornatus responderam, juntas, por $98,3 \%$ da biomassa total, sendo que apenas as duas primeiras espécies contribuíram com 92,4\% (Tabela 5). A menor biomassa total foi observada no ponto 2 , e as maiores no ponto 5 (com elevados valores de $C$. danae e $C$. sapidus), e no ponto 3, composto principalmente por $C$. danae. Apesar da sua baixa abundância total (Tabela 4), C. sapidus apresentou elevada biomassa ( $20 \%$ do total). Ao contrário, $C$. ornatus, cuja abundância foi similar à de $C$. sapidus, mostrou valores bem mais baixos de biomassa (Tabelas 4 e 5). Os camarões contribuíram com $4,7 \%$ da biomassa total capturada, sendo que 3,6\% corresponderam a X. kroyeri (Tabela 5).

A variação temporal da abundância e da biomassa das cinco principais espécies capturadas no estudo pode ser observada na Figura 5. De forma geral, as espécies de Callinectes apresentaram abundância e biomassa crescentes, após a enchente, entre janeiro e julho de 2009. C. danae foi a única espécie do gênero com elevada ocorrência em 2008, enquanto C. sapidus foi a espécie mais importante nos meses imediatamente posteriores a enchente, em dezembro de 2008 e janeiro de 2009, ainda que em quantidades reduzidas. Pode-se destacar ainda um grande aumento na abundância e biomassa dessa espécie entre junho e julho de 2009 e um grande aumento na biomassa de $C$. ornatus entre maio e junho de 2009. Entre os camarões, $X$. kroyeri ocorreu apenas uma vez em 2008 e em quantidades muito baixas, porém, apresentou abundância e biomassa elevadas entre fevereiro e abril de 2009. Já F. paulensis ocorreu nas amostragens entre junho e setembro de 2008 em 

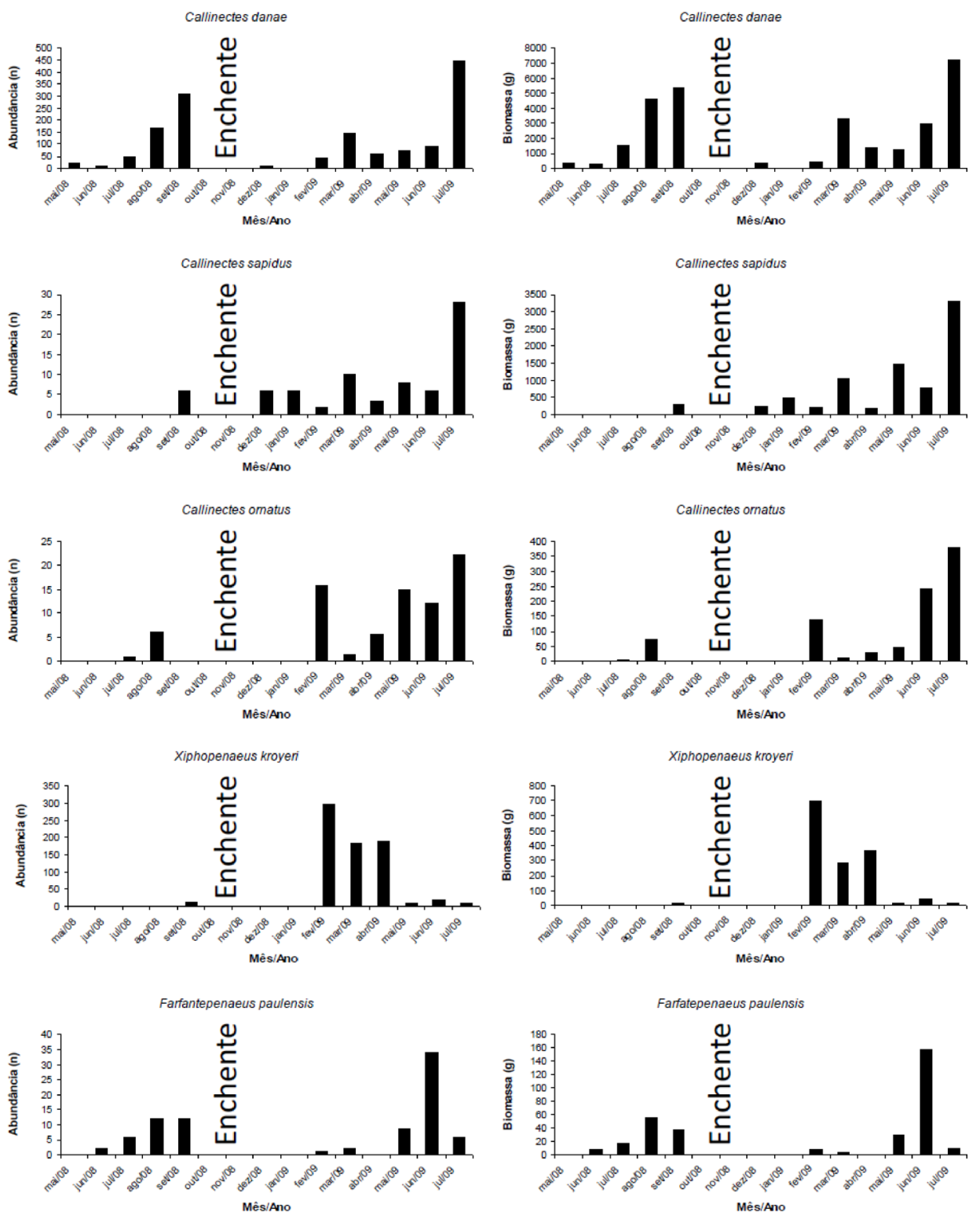

Figura 5 - Distribuição temporal da abundância $(n)$ e biomassa $(g)$ das principais espécies coletadas no estuário do rio Itajaí-Açu entre maio de 2008 e julho de 2009. Em outubro e novembro de 2008 não foram realizadas amostragens.

baixas quantidades, apresentando máxima ocorrência em junho de 2009.

A correlação entre a abundância das principais espécies e as variáveis ambientais, no geral, foram baixas e pouco significativas (Tabela 6 ). A salinidade e a temperatura foram as variáveis em que se observou os valores mais significativos, sendo que a primeira mostrou correlação positiva com C. danae, C. ornatus e F. paulensis e a temperatura apresentou correlação negativa com C. danae e F. paulensis e positiva com $X$. kroyeri. As variáveis OD e pH tiveram correlações negativas com as espécies $X$. kroyeri e $C$. sapidus, respectivamente (Tabela 6).

Com o objetivo de identificar sob quais condições ambientais as principais espécies foram obser- vadas ao longo do estudo, foi analisada a distribuição dos valores de salinidade, temperatura, oxigênio dissolvido e pH em que cada espécie foi coletada (Figura 6). Para todas as espécies a mediana dos valores de salinidades esteve situada entre 25 e 30 , porém, as espécies não se comportaram de forma homogênea. Como exemplo, C. ornatus mostrou distribuição mais restrita, tendendo a ocorrer somente em salinidades acima de 25 , enquanto $C$. sapidus esteve presente em salinidades bem menores chegando a ser coletada em valores próximos a 2 . Já $C$. danae apresentou um padrão mais intermediário, predominando também em salinidades elevadas, mas com ocorrência relativamente comum em valores próximos a 15 e, esporadicamente, em salinidades mais baixas (Figura 6). 
Tabela 6 - Correlação de Spearman entre a abundância das principais espécies e as variáveis ambientais no estuário do rio Itajaí-Açu entre maio de 2008 a julho de 2009. * = correlação significativa $(p<0,05)$.

\begin{tabular}{lcccc}
\hline \hline \multicolumn{1}{c}{ Espécies } & Salinidade & Temperatura $\left({ }^{\circ} \mathrm{C}\right)$ & $\mathrm{pH}$ & $\mathrm{OD}(\mathrm{mg} / \mathrm{l})$ \\
\hline Callinectes danae & $0,430^{*}$ & $-0,272^{*}$ & $-0,042$ & $-0,117$ \\
Callinectes sapid us & $-0,020$ & 0,0934 & $-0,285^{*}$ & $-0,138$ \\
Callinectes ornatus & $0,390^{*}$ & $-0,016$ & 0,094 & $-0,055$ \\
Farfantepenaeus paulensis & $0,235^{*}$ & $-0,234^{*}$ & 0,007 & $-0,140$ \\
Xiphopenaeus kroyeri & 0,191 & $0,256^{*}$ & $-0,037$ & $-0,238^{*}$ \\
\hline \hline
\end{tabular}

C. danae e F. paulensis foram encontradas, mais frequentemente, abaixo dos $20^{\circ} \mathrm{C}$, enquanto as demais espécies ocorreram preferencialmente acima de $21^{\circ} \mathrm{C}$. X. kroyeri e C. sapidus apresentaram padrões muito similares, com maior freqüência em águas mais quentes, enquanto F. paulensis foi totalmente distinto, com distribuição mais restrita a temperaturas mais reduzidas. Já $C$. ornatus e $C$. danae apresentaram padrão intermediário (Figura 6).

A mediana do OD para todas as espécies ficou entre 5 e $6 \mathrm{mg} / \mathrm{l}$. C. ornatus e $X$. kroyeri apresentaram padrão similar ocorrendo em concentrações entre 2 a $9 \mathrm{mg} / \mathrm{l}$. Já $C$. sapidus foi a espécie com distribuição mais restrita, deixando de ocorrer em teores de OD abaixo de 3,5 mg/l. Já $C$. danae e $F$. paulensis foram as mais tolerantes a baixas concentrações (Figura 6).

Os valores da mediana do $\mathrm{pH}$ foram próximos para todas as espécies, oscilando entre 7,8 e 8,0
(Figura 6). C. danae e F. paulensis apresentaram padrão de distribuição similar, porém, a primeira espécie foi observada apenas esporadicamente em baixos valores de $\mathrm{pH}$. Em valores abaixo de 7,5, a única espécie com ocorrência relativamente comum foi $C$. sapidus. A espécie mais restrita com relação a essa variável foi $C$. ornatus (Figura 6).

\section{DISCUSSÃo}

Considerando a literatura disponível sobre a hidrologia e demais aspectos físico-químicos do estuário do rio Itajaí-Açu (Schettini \& Truccolo, 2009; Kuroshima \& Bellotto, 2009), pode-se verificar que o comportamento das variáveis ambientais estudadas neste trabalho foi compatível com os padrões já reportados anteriormente para a região.
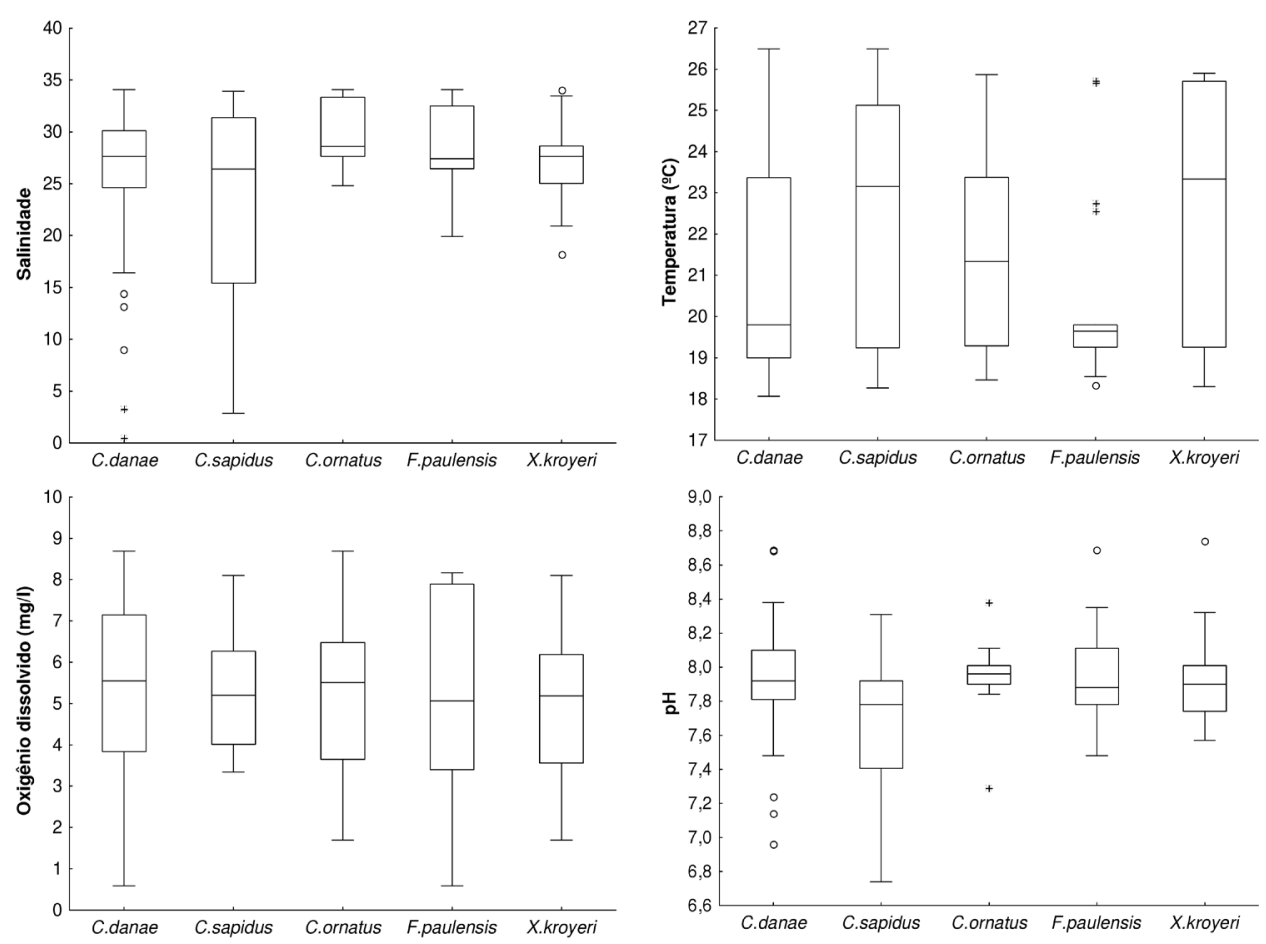

Figura 6 - Box-plot dos valores de salinidade, temperatura $\left({ }^{\circ} \mathrm{C}\right)$, concentração de oxigênio dissolvido $(\mathrm{mg} / \mathrm{l})$ e pH, em que as principais espécies foram coletadas entre maio de 2008 a julho de 2009. As linhas e limites inferiores e superiores das caixas representam a mediana e os percentis de $25 \%$ e $75 \%$, respectivamente. Os limites das barras são máximos e mínimos freqüentes. Asteriscos e pontos são outliers e extremos, respectivamente. 
Eventos de pluviosidade acima da média na bacia hidrográfica do rio Itajaí-Açu, como ocorrido em novembro de 2008, podem levar a completa expulsão da cunha salina do estuário o que resulta em grandes mudanças físico-químicas. Após a enchente foi observada uma redução na salinidade, $\mathrm{pH}$, e oxigênio dissolvido no baixo estuário, que permaneceram alterados até fevereiro de 2009 (Figura 3). Essas variáveis apresentam maiores valores na água do mar e, como consequência, são reduzidas quando há uma maior contribuição de águas continentais no estuário.

A enchente provocou ainda, o assoreamento do canal de acesso ao porto. Como conseqüência, em dezembro de 2008 teve início uma grande dragagem emergencial que teve continuidade até julho de 2009. Isso explica o gradativo aumento da profundidade nos pontos 1-3 durante o período (Tabela 2). Outro possível efeito da dragagem foi a diminuição do $\mathrm{pH}$ e do OD entre maio e julho de 2009 em relação ao mesmo período de 2008 (Figura 3). Durante o processo de dragagem ocorre a suspensão de sedimentos finos, que podem ser ricos em matéria orgânica e provocar a redução do oxigênio dissolvido e do pH (Ohimain et al., 2008; Erftemeijer \& Lewis, 2006; Torres, 2000).

Foram observados, no ponto 3 , valores de OD próximos a zero no mês de agosto de 2008, cuja origem não foi possível se determinar. Em alguns pontos, os valores dessa variável foram mínimos em fevereiro de 2009, representando um possível efeito combinado da dragagem, da estratificação do estuário, das temperaturas mais elevadas neste período (que diminuem a solubilidade dos gases) e da enorme quantidade de detritos orgânicos depositados na região após a enchente de novembro de 2008.

A assembléia de decápodos caracterizou-se por poucas espécies (14), assim como foi encontrado no complexo lagunar Mundaú/Manguaba (Alagoas), onde foram capturadas 15 espécies (Teixeira \& Sá, 1998). Branco \& Freitas Jr. (2009) observaram o mesmo padrão no Saco da Fazenda, uma enseada rasa protegida, situada na margem direita da foz do Itajaí-Açu, onde foram registradas dez espécies de siris e camarões ao longo de cinco anos de amostragens. Essa baixa riqueza pode ser função da ampla flutuação das variáveis ambientais que ocorrem nos estuários e consequentes condições de estresse a que os organismos estuarinos estão submetidos (Angonesi, 2005). A ocorrência ocasional de algumas espécies em abundâncias bastante reduzidas foi observada neste estudo, como a espécie exótica Charybdis hellerii, com apenas quatro indivíduos e Litopenaeus schmitti com apenas um indivíduo. Das 14 espécies coletadas, somente cinco ( $C$. danae, $C$. ornatus, C. sapidus, F. paulensis e $X$. kroyeri) foram responsáveis por $98,6 \%$ da abundância total. Essa dominância de poucas espécies também foi observada para a ictiofauna do estuário do Itajaí-Açu, onde seis espécies contribuíram com $99 \%$ das capturas efetuadas durante o mesmo período e nas mesmas estações amostradas no presente estudo (Antunes, 2010). Segundo esta autora, isso pode estar associado ao acúmulo de perturbações antrópicas no sistema, como as dragagens e alterações nas margens do estuário, como também a perturbação natural, incluindo a grande enchente de novembro de 2008 , a qual causou alterações imediatas e severas na assembléia de peixes do estuário, gerando redução na abundância das principais espécies (Antunes, 2010).

Verificando a distribuição espacial dos crustáceos ao longo do estuário foi possível observar uma elevada abundância média no ponto mais externo, reflexo da grande presença de $X$. kroyeri, espécie marinha bastante capturada pela pesca artesanal no litoral catarinense. Também foi possível observar uma elevada abundância total no ponto 4, representada principalmente por Callinectes spp. A elevada densidade desse gênero nos pontos de salinidade intermediária como o ponto 4 (salinidade média de 24) também foi observada por Pereira (2006), que encontrou maiores abundâncias em locais de salinidade em torno de 23 na baia da Babitonga, situada no litoral norte de Santa Catarina.

A abundância de decápodos foi mínima nos meses imediatamente seguintes à enchente (dezembro de 2008 e janeiro de 2009), provavelmente em decorrência do efeito agudo deste fenômeno sobre a distribuição e/ou mortalidade da fauna. Crustáceos decápodos podem não conseguir reagir a rápida entrada de água doce em um evento de vazão extrema (Paperno \& Brodie, 2004) e, portanto, esse tipo de evento é capaz de afetar significativamente o bentos estuarino (Cardoso et al., 2008). Por outro lado, os decápodos foram capazes de se recuperar da enchente nos meses seguintes, como atestam as elevadas abundâncias e biomassas registradas entre maio e julho de 2009. Padrão idêntico foi reportado por Antunes (2010), com relação à ictiofauna local. A recuperação da fauna após um evento extremo demonstra a sua resiliência. Entretanto, deve-se considerar que a resiliência dos estuários tende a diminuir quando a frequência de impactos aumenta, principalmente em estuários poluídos, como o do rio Itajaí-Açu (Dugan \& Livingston, 1982), o que demandaria atenção na região, considerando o provável aumento da ocorrência de eventos extremos como esse no futuro, em razão das modificações climáticas globais.

Os valores de abundância e biomassa totais registrados entre maio e julho de 2008 foram inferiores aos do mesmo período de 2009. Além disso, nesse último ano foi observada a ocorrência isolada de algu- 
mas espécies, como aquelas da família Palaemonidae, Hippolytidae sp., e os camarões Litopenaeus schmitti, Artemesia longinaris e Caridea sp. Esse aumento de abundância e de riqueza no segundo ano do estudo poderia ser ocasionada, por exemplo, pela criação de habitats em função do entulho depositado no fundo do estuário pela enchente e/ou pela disponibilização de recursos alimentares trazidos pelo rio. Entretanto, não se pode descartar os possíveis efeitos da dragagem que teve início em dezembro de 2008. O aprofundamento do canal pode promover melhorias nos padrões de circulação (Torres, 2000) e, consequentemente, facilitar uma maior penetração da cunha salina, trazendo assim espécies marinhas ao estuário.

Durante o estudo foi registrada a espécie de siri Charybdis helleri, invasora e original do Indo Pacífico (Mantelatto \& Garcia, 2001). Existe risco desse siri competir com espécies nativas de Callinectes, além de ser hospedeiro potencial do vírus WSSV (Síndrome da Mancha Branca) (Tavares \& Mendonça Jr., 2004). Isso mostra que o estuário do rio Itajaí-Açu está sujeito a bioinvasão, principalmente se considerarmos a grande quantidade de navios que atracam nos portos de Itajaí e Navegantes.

As espécies mais abundantes e que apresentaram a maior freqüência de ocorrência foram Callinectes danae, Xiphopenaeus kroyeri, Farfantepenaeus paulensis, $C$. ornatus e $C$. sapidus. $O$ siri $C$. danae esteve presente em todos os pontos, assim como observado por Pereira et al. (2009), que coletaram siris do gênero Callinectes tanto junto à foz como em três pontos do interior da Baía da Babitonga, São Francisco do Sul, SC. C. danae foi observado em quase todos os meses de amostragem do presente estudo, contribuindo com as maiores abundâncias durante o período, o que segue padrão encontrado em vários trabalhos ao longo do litoral sudeste-sul do Brasil (Lunardon-Branco \& Branco, 1993; Pereira et al., 2009). A espécie foi mais abundante em julho de 2009, mês em que a temperatura foi baixa, em torno dos $18^{\circ} \mathrm{C}$, e nos pontos mais internos do estuário (ocupando preferencialmente os pontos 3, 4 e 6 ), em salinidades altas entre 25 e 30 . Porém, no estudo de Macedo-Soares et al. (2009) na Baía Norte em Florianópolis/SC, a abundância foi maior na primavera com ocorrência durante todo o ano. Branco \& Masunari (2000) também verificaram pico de abundância na primavera na Lagoa da Conceição em Florianópolis, porém os autores observaram que no ponto fora da laguna a abundância foi maior no inverno.

Callinectes sapidus foi a segunda espécie mais importante em termos de abundância, assim como encontrado por Branco \& Freitas Jr. (2009) e Pereira (2006), no Saco da Fazenda e na Baia da Babitonga, respectivamente. Assim como todas as espécies do gênero, ela foi mais abundante em julho de 2009, e foi a única espécie de Brachyura que prevaleceu em dezembro de 2008 e janeiro de 2009, logo após a enchente, o que pode ser explicado pela tolerância da espécie a baixas salinidades (Ogburn et al., 2007) e a ambientes bastante poluídos (Rodrigues, 2006). De fato, no presente estudo, verificou-se que a espécie foi observada numa ampla faixa de salinidade, reforçando seu caráter tolerante a essa condição.

Callinectes ornatus também foi uma das cinco principais espécies amostradas, porém correspondeu a apenas 3,3\% dos indivíduos. Essa baixa porcentagem também foi encontrada por Branco \& Freitas Jr. (2009) no Saco da Fazenda. Participações mais elevadas dessa espécie já foram registradas na Planície da Praia Leste, litoral do Paraná (Lunardon-Branco \& Branco, 1993), na baia de Ubatuba, São Paulo, onde a espécie é dominante (Mantelatto \& Fransozo, 2000) e também na Armação do Itapocoroy, Santa Catarina (Branco, 1999). O fato desses três trabalhos terem sido realizados em ambiente marinho, mostrando maiores percentuais de ocorrência da espécie, enquanto no presente trabalho sua ocorrência foi apenas ocasional, indica a preferência desse siri pelo habitat marinho, ao contrário de $C$. sapidus e de $C$. danae que seriam mais estuarinos. Isso é corroborado pela ocorrência de C. ornatus apenas nas maiores salinidades registradas durante este estudo (Figura 6) e pela correlação positiva da sua abundância com a mesma variável.

O camarão sete-barbas $X$. kroyeri contribuiu com $29,7 \%$ dos indivíduos amostrados, contra $4,3 \%$ da participação das demais espécies de camarões. A espécie se distribuiu ao longo de todo o perfil, provavelmente em função da penetração da cunha salina, uma vez que é considerada uma espécie marinha que não depende dos estuários para o desenvolvimento dos seus juvenis, embora já tenha sido reportada neste tipo de ambiente por alguns autores (Valentini et al., 1991a). Apesar da elevada abundância desse camarão junto a foz, não foi observada uma correlação significativa com a salinidade, sendo registrados indivíduos em salinidades entre 21 e 34 . Esses valores são praticamente idênticos aos observados por Branco et al. (1999) na área marinha situada em frente às praias de Navegantes e Atalaia (15 m de profundidade), localizadas imediatamente ao norte e ao sul da desembocadura do Itajaí-Açu. Nesses locais, o camarão sete-barbas foi observado em salinidades médias entre 20 e 35 , as quais, segundo os autores, foram largamente influenciadas pelas oscilações na descarga do estuário. No presente trabalho verificouse que $X$. kroyeri teve um incremento em abundância entre fevereiro e abril de 2009 e queda a partir de maio, mesmo padrão observado por Branco et al. (1999) e Branco (1999), na Foz do Itajaí Açu e na Armação do 
Itapocoroy (Penha-SC), respectivamente. Pezzuto et al. (2008) estudando a pesca de $X$. kroyeri na região entre Florianópolis e Bombinhas, Santa Catarina, verificou que a espécie apresenta maior abundância entre fevereiro e junho, o que explicaria os resultados encontrados nesse trabalho, pois havendo maior disponibilidade dessa espécie na zona costeira adjacente, isso aumentaria a probabilidade dela entrar no estuário acompanhando a cunha salina.

Embora possua extrema importância comercial e também seja um dos principais predadores de macroinvertebrados bentônicos no estuário da Lagoa dos Patos (Valentini et al., 1991b; Bemvenuti, 1987), o camarão-rosa F. paulensis foi pouco abundante no Itajaí-Açu. Ele foi observado em quase todos os meses, com pico em junho de 2009, diferente do encontrado por Lopes (2008), que registrou maiores abundâncias da espécie no outono e mínimas na primavera em estuários de Ubatuba. A espécie apresentou correlação negativa com a temperatura, ao contrário do observado por Branco \& Verani (1998) na Lagoa da Conceição (Florianópolis - SC). A reprodução da espécie ocorre o ano todo (Valentini et al., 1991b) e a migração dos juvenis dos estuários para o oceano ocorre principalmente entre fevereiro e maio (Valentini et al., 1991b). Dessa forma, é provável que outros fatores possam ter minimizado a sua captura durante o verão, entre eles a dragagem, que teve início em dezembro de 2008, a elevada vazão do rio e ainda o pH que atingiu valores mínimos no período.

Os resultados obtidos no presente trabalho mostram uma extrema dominância de poucas espécies de decápodos no Itajaí-Açu, sugerindo elevada frequência e intensidade de variações ambientais, sejam elas de cunho natural ou antrópico. Além dessa variabilidade "natural", eventos episódicos de intensidade extrema como a enchente de 2008, podem ocasionar impactos agudos na assembleia, reduzindo sua abundância e riqueza nos meses subsequentes. Contudo, e a despeito da magnitude do evento, tais impactos não pareceram ter efeitos permanentes, visto os incrementos de abundância e de riqueza observados poucos meses depois. Evidências conclusivas a respeito do papel dessa dinâmica ambiental sobre os organismos dependeriam de uma amostragem com maior amplitude temporal, englobando períodos do ano semelhantes, sem a ocorrência de eventos extremos como o observado no presente estudo (i. e. réplicas temporais).

\section{AGRADECIMENTOS}

Este trabalho foi realizado como Trabalho de Conclusão de Curso de Oceanografia de I.P.L., no âmbito do projeto "Impactos de enchente, dragagem de aprofundamento e dinâmica estuarina sobre a ictiofauna no estuário do rio Itajaí-Açu, SC, Brasil", desenvolvido pela MSc. Aline Antunes e pelo Dr. Paulo Ricardo Schwingel (CTTMar/UNIVALI), a quem os autores agradecem a oportunidade de participação. O projeto teve apoio financeiro do Programa PRoBIC/ UNIVALI.

\section{REFERÊNCIAS BIBLIOGRÁFICAS}

Angonesi, L. G. 2005. Dinâmica de curto prazo da macrofauna bentônica em uma enseada estuarina da Lagoa dos Patos: efeitos antrópicos e mecanismos de persistência e resiliência. Tese de doutorado. Fundação Universidade Federal do Rio Grande. 163 p.

Antunes, A. 2010. Impactos da enchente, dragagem de aprofundamento e dinâmica estuarina sobre a ictiofauna no estuário do rio Itajaí-Açu, SC, Brasil. Tese de mestrado. Ciência e Tecnologia Ambiental - Universidade do Vale do Itajaí. 102 p.

Bemvenuti, C. E. 1987. Macrofauna bentônica da região estuarial da Lagoa dos Patos, RS, Brasil. In: I Simpósio sobre Ecossistemas da Costa Sul e Sudeste Brasileira - Síntese dos Conhecimentos, Cananéia: ACIESP, 54: 428 - 459.

Branco, J. O. \& Verani, J. R. 1998. Estudo populacional do camarão-rosa Penaeus paulensis Perez Farfante (Natantia, Penaeidae) na Lagoa da Conceição, Santa Catarina, Brasil. Rev. Bras. Zool. 15(2): 353-364.

Branco, J. O.; Lunardon-Branco, M. J.; Souto, F. X. \& Guerra, C. R. 1999. Estrutura populacional do camarão sete-barbas Xiphopenaeus kroyeri (Heller, 1862), na foz do rio Itajaí-Açú, Itajaí, SC, Brasil. Braz. Arch. Biol. Technol. 42(1): 115-126.

Branco, J. O. 1999. Biologia do Xiphopenaeus kroyeri (Heller, 1862) (Decapoda: Penaeidae), análise da fauna acompanhante e das aves marinhas relacionadas a sua pesca, na região de Penha, SC-Brasil. Tese de doutorado. Centro de Ciências Biológicas e da Saúde - Universidade Federal de São Carlos. 149 p.

Branco, J. O. \& Masunari, S. 2000. Reproductive ecology of the blue crab, Callinectes danae Smith, 1869 in the Conceição Lagoon System, Santa Catarina Isle, Brazil. Rev. Bras. Biol. 60(1): 17-27.

Branco, J. O. \& Freitas Jr, F. 2009. Análise qualiquantitativa dos crustáceos no ecossistema Saco da Fazenda, Itajaí, SC. In: Branco, J. O.; LunardonBranco M. J. \& Bellotto V. R. (eds.) Estuário do rio Itajaí-Açu, Santa Catarina: Caracterização 
Ambiental e Alterações Antrópicas. UNIVALI. 180 $-206 \mathrm{pp}$.

Cardoso, P. G.; Raffaelli, D.; Lilleb. A.I.; Verdelhos, T. \& Pardal, M.A. 2008. The impact of extreme flooding events and anthropogenic stressors on the macrobenthic communities dynamics. Estuar. Coast. Shelf Sci. 76: $553-565$.

Coelho, P. A. \& Santos, M. C. F. 2003. Ocorrência de Charybdis hellerii (Milne Edwards, 1867) (Crustacea, Decapoda, Portunidae) no litoral de Pernambuco. Bolm. Tec. Cient. CEPENE. 11(1): $167-173$.

Costa, R. C.; Fransozo, A.; Melo, G. A. S. \& Freire, F. A. M. 2003. Chave ilustrada para identificação dos camarões Dendrobranchiata do litoral norte do estado de São Paulo, Brasil. Biota Neotropica. 3(1): BN01503012003.

Dame, R. F. \& Allen, D. M. 1996. Between estuaries and the sea. J. Exp. Mar. Biol. Ecol. 169-185.

Day Jr, J. W.; Hall, C. A. S.; Kemp, W M \& YánezArancibia, A. 1989. Estuarine ecology. John Wiley, New York, $558 \mathrm{p}$.

D'Incao, F. 1995. Taxonomia, padrões distribucionais e ecológicos dos Dendrobranchiata (Crustacea: Decapoda) do Brasil e Atlântico Ocidental. Tese de Doutorado. Universidade Federal do Paraná. $365 \mathrm{p}$.

Dugan, P. J \& Livingston, R. J. 1982. Long-term Variation of Macroinvertebrate Assemblages in Apalachee Bay, Florida. Estuar. Coast. Shelf Sci.14: 391-403.

Erftemeijer, P. L. A. \& Lewis, R. R. R. 2006. Environmental impacts of dredging on seagrasses: A review. Mar. Pollut. Bull. 52: 1553-1572.

Ferreira, L. S. \& D'Incao, F. 2008. Crescimento de Callinectes sapidus (Crustacea, Decapoda, Portunidae) no estuário da laguna dos Patos, RS, Brasil. Iheringia. Série Zoologia. 98(1): 70-77.

Kapusta, S. C. 2005. Padrões espaciais da comunidade de invertebrados bentônicos no estuário TramadaíArmazém, RS, e a resposta da macro e meiofauna a um derrame experimental de óleo bruto. Tese de doutorado. Universidade Federal do Rio Grande do Sul. $126 \mathrm{p}$.

Kuroshima, K. N. \& Bellotto, V. R. 2009. Dinâmica dos nutrientes inorgânicos e orgânicos na foz do rio Itajaí-Açú. In: Branco, J. O.; Lunardon-Branco M. J. \& Bellotto V. R. (eds.) Estuário do rio ItajaíAçu, Santa Catarina: Caracterização Ambiental e Alterações Antrópicas.UNIVALI. 93 - 104 pp.

Lopes, M. 2008. Ecologia populacional dos camarõesrosa, Farfantepenaeus brasiliensis (Latreille, 1817) e F. paulensis (Pérez-Farfante, 1967) (Decapoda: Dendrobranchiata: Penaeidae) em áreas de berçário do litoral norte de São Paulo. Tese de mestrado. Universidade Estadual Paulista. 204 p.

Lunardon-Branco, M. J. \& Branco, J. O. 1993. A Fauna de Brachyura acompanhante de Menticirrhus littoralis (Holbrook, 1860) na região de Matinhos e Caiobá, litoral do Paraná, Brasil. Arq. Biol. Tecnol. 36(3): 479-487.

Macedo-Soares, L. C. P. Moreira, M.C.; Silva, B.C. \& Freire, A.S. 2009. Estrutura populacional e biologia reprodutiva do siri Callinectes danae Smith, 1869 (Decapoda: Portunidae) na Baía Norte, Florianópolis, Santa Catarina, Brasil. In: Anais do III Congresso Latino Americano de Ecologia. São Lourenço. Disponível em <http://www.sebecologia.org.br/2009/resumos_clae/436.pdf>

Mantelatto, F. L. M. \& Fransozo, A. 2000. Brachyuran community in Ubatuba bay, northern coast of São Paulo state, Brazil. J. Shellfish Res. 19(2): $691-700$.

Mantelatto, F. L. M. \& Garcia, R. B. 2001. Biological aspects of the nonindigenous Portunid crab Charybdis hellerii in the western tropical south atlantic. Bull. Mar. Sci. 68(3): $469-477$.

Melo, G. A. S. 1996. Manual de Identificação dos Brachyura (Caranguejos e Siris) do Litoral Brasileiro. São Paulo, Plêiade/FAPESP. 603 p.

Miranda, L. B.; Castro, B. M. \& Kjerfve, B. 2002. Princípios de oceanografia física de estuários. São Paulo, Editora da Universidade de São Paulo. $424 \mathrm{p}$.

Ogburn, M. B.; Jackson, J. L. \& Forward Jr, R. B. 2007. Comparison of low salinity tolerance in Callinectes sapidus Rathbun and Callinectes similis Williams postlarvae upon entry into an estuary. J. Exp. Mar. Biol. Ecol. 352(2): 343-350.

Ohimain,E. I.; Imoobe, T. O. \& Bawo, D. D. S. 2008. Changes in Water Physico-Chemical Properties Following the Dredging of an Oil Well Access Canal in the Niger Delta. World J. Agric. Sci. 6(4): 752-758.

Paperno, R. \& Brodie, R. B. 2004. Effects of environmental variables upon the spatial and temporal structure of a fish community in a small, freshwater tributary of the Indian River Lagoon, Florida. Estuar. Coast. Shelf Sci. 61: 229 -241.

Pereira, M. J. 2006. Estrutura populacional do gênero Callinectes na Baía da Babitonga, São Francisco do Sul, SC. Tese de mestrado. Universidade do Vale do Itajaí. $61 \mathrm{p}$.

Pereira, M. J.; Branco, J. O.; Christoffersen, M. L.; Freitas Jr., F.; Fracasso, H. A. A. \& Pinheiro, T. C. 2009. Population biology of Callinectes danae and Callinectes sapidus (Crustacea: Brachyura: Portunidae) in the south-western Atlantic. J. Mar. Biol. Assoc. U. K. 89(7): 1341 - 135. 
Pezzuto, P. R.; Alvarez-Perez, J. A. \& Wahrlich, R. 2008. The use of the swept area method for assessing the seabob shrimp Xiphopenaeus kroyeri (Heller, 1862) biomass and removal rates based on artisanal fisheryderived data in southern Brazil: using depletion models to reduce uncertainty. Lat. Am. J. Aquat. Res. 36(2): 245-257.

Porath, S. L. 2004. A paisagem de rios urbanos: A presença do rio Itajaí-Açu na cidade de Blumenau. Tese de Mestrado. Universidade Federal de Santa Catarina.150 p.

Rodrigues, M. A. 2006. Crescimento e ciclo de mudas de Callinectes sapidus (Rathbun, 1896) no estuário da Lagoa dos Patos. Tese de mestrado. Fundação Universidade Federal do Rio Grande. 83 p.

Schettini, C. A. F. 2001. Dinâmica de sedimentos finos no estuário do rio Itajaí-Açu, SC. Tese de Doutorado. Universidade Federal do Rio Grande do Sul. 91p.

Schettini, C. A. F. \& Truccolo, E. C. 2009. Circulação do baixo estuário do rio Itajaí. In: Branco, J. O.; Lunardon-Branco M. J. \& Bellotto V. R. (eds.) Estuário do rio Itajaí-Açu, Santa Catarina: Caracterização Ambiental e Alterações Antrópicas. UNIVALI. $13-26$ pp.

Tavares, M. \& Mendonça Jr, J. B. 2004. Introdução de crustáceos decápodes exóticos no Brasil: uma roleta ecológica. In: Silva, J. S. V. \& Souza, R. C. C. L. 2004. Água de Lastro e Bioinvasão. Interciência. 59-76 pp.
Teixeira, R. L. \& Sá, H. S. 1998. Abundância de macrocrustáceos decápodas nas áreas rasas do complexo lagunar Mundaú/Manguaba, AL. Rev. Bras. Biol. 58(3): 393-404.

Torres, R. J. 2000. Uma análise preliminar dos processos de dragagem do porto de Rio Grande, RS. Tese de Mestrado. Fundação Universidade Federal do Rio Grande.190 p.

Valentini, H. F.; D'Incao, L. F.; Rodrigues, J. E.; Rebelo Neto, J. E. \& Domit, L. G. 1991a. Análise da pesca do camarão sete-barbas (Xiphopenaeus kroyeri) nas regiões sudeste e sul do Brasil. Atlântica, Rio Grande. 13(1): 171 - 177.

Valentini, H. F.; D'Incao, L. F.; Rodrigues, J. E.; Rebelo Neto, J. E. \& Rahn, E. 1991b. Análise da pesca do camarão-rosa (Penaeus brasiliensis e Penaeus paulensis) nas regiões sudeste e sul do Brasil. Atlântica, Rio Grande.13(1): 143 - 157.

Veado, L. 2008. Variação espaço-temporal do zooplâncton do baixo estuário do rio Itajaí-Açu, SC. Tese de Mestrado. Universidade do Vale do Itajaí. $71 \mathrm{p}$. 